\title{
Memória de atos regulatórios na comunicação na UFRGS: uma proposta analítica ${ }^{1}$
} Ana Luiza Coiro-Moraes \& Édina Maria da Rocha Ferreira

\section{Resumo}

Referendando-se teoricamente em Hall (1997), este artigo propõe uma reflexão sobre os atos regulatórios relativos ao setor de comunicação da Universidade Federal do Rio Grande do Sul (UFRGS), com ênfase na memória da Assessoria de Imprensa. Através de pesquisa documental, examinamos as atribuições e os objetivos pelos quais a Universidade e 0 setor foram regulados, detendo-nos nos períodos ditatoriais e sob o neoliberalismo, concluindo que se nestes a tendência é a desregulação, as ditaduras se caracterizam pela regulação da cultura. Finalmente, discutimos, nos dias de hoje, como a Assessoria de Imprensa vem sistematizando atividades e criando normas e políticas para sua atuação.

\section{Palavras-Chave}

Memória institucional. Cultura.

Regulação da Comunicação.
Ana Luiza Coiro-Moraes I anacoiro@gmail.com Professora Colaboradora do Programa de Pós-Graduação em Comunicação da Universidade Federal de Santa Maria - UFSM, Brasil. Doutora em Comunicação Social pela Pontifícia Universidade Católica do Rio Grande do Sul - PUCRS, Brasil. Realizou estágio Pós-Doutoral em Comunicação e Cultura pela Universidade Federal da Bahia - UFBA, Brasil.

\section{Édina Maria da Rocha Ferreira}

l edinarocha2@hotmail.com

Mestranda em Memória Social e Bens Culturais por meio do Centro Universitário La Salle - Unilasalle, Brasil. Especialista em Estudos Linguísticos do Texto pela Universidade Federal do Rio Grande do Sul - UFRGS, Brasil. É assessora de imprensa da mesma instituição.

\section{Introdução}

Conduzidas pelo debate acerca da regulação da cultura promovido por Hall (1997), propomos uma reflexão sobre os atos regulatórios que formalizaram desde a criação da Universidade Federal do Rio Grande do Sul (UFRGS) até a constituição da Secretaria de Comunicação Social.

No âmbito da regulação da cultura e de sua centralidade nos debates sobre políticas públicas, Hall (1997) aponta o papel do Estado, cujo poder atua no sentido da sistematização de práticas e políticas culturais, por meio de normas e regras. Há, contudo, rupturas no contexto da regulação cultural, que, ao final, demarcam o pertencimento e o que está "fora dos limites discursivos e normativos" (HALL, 1997, p. 234).

Assim, posicionadas em dois momentos de ruptura na ordem democrática brasileira, através de pesquisa documental, identificando, verificando e analisando as fontes primárias que constituem o seu corpus (MOREIRA, 
2008), examinamos: 0 Decreto $\mathrm{n}^{0} 5.758$, de 28/11/1934, pelo qual Vargas criava a Universidade de Porto Alegre às vésperas do Estado Novo; e a Portaria ${ }^{0} 729$, de 22/08/1972, que, em plena ditadura militar, instituía a Assessoria de Imprensa da UFRGS.

E, sob a égide do neoliberalismo, em que Hall (1997) reconhece uma tendência à desregulação da cultura associada ao mercado, analisamos ainda a Portaria $\mathrm{n}^{0} 4356$, de 13/10/1993, a qual visava "implantar um sistema integrado de comunicação social"; e a criação da Secretaria de Comunicação Social, em portaria ( $\mathrm{n}^{0} 2482$, de 07/10/2004) que não institui atribuições à comunicação, em sinal de novos tempos senão de desregulação, de enxugamento dos normativos regulatórios.

Para tanto, este texto se organiza, em primeiro lugar, articulando um breve debate sobre memória e pesquisa documental, para, a seguir, esboçar uma proposta analítica de natureza qualitativa, centrada no conceito de regulação da cultura. Depois, a seção seguinte traz um breve histórico sobre a trajetória da Universidade, outra se dedica à discussão do papel da assessoria de imprensa da UFRGS e, finalmente, apresentamos as considerações que encerram 0 artigo.

\section{Sobre memória institucional e pesquisa documental}

Atenta ao caráter interdisciplinar do campo da comunicação, Moreira (2005, p. 276) indica que a análise documental, mais do que localizar, identificar, organizar e avaliar documentos, quaisquer que sejam os suportes que os veiculem, é um instrumento eficaz para "contextualizar fatos, situações momentos", e aponta como uma de suas possíveis fontes primárias de consulta os documentos oficiais das instituições. Ela lembra, também, que 0 trabalho de análise documental pressupõe

[...] o conhecimento daquilo que a legislação brasileira prevê em relação a arquivos. [...] 0 art. $2^{\circ}$ [da Lei de Arquivos] considera como arquivos "os conjuntos de documentos produzidos e recebidos por órgãos públicos, instituições de caráter público e entidades privadas, [...] bem como por pessoa física, qualquer que seja 0 suporte da informação ou a natureza dos documentos ${ }^{2 \prime}$.

Assim, para falarmos sobre memória das instituições, retomamos a definição de Icleia Costa (1997, p. 5): "as instituições são tomadas como forma fundamental) de saber e poder, que emergem no seio das sociedades e possuem duas faces simétricas: lembrar e esquecer, pois a memória, como alvo político, passa por

Artigo desenvolvido a partir de trabalho apresentado no GT 2: Comunicação Organizacional e Relações Públicas, com inserção no subtema Narrativas y formaciones discursivas emergentes de la comunicación do VIII Seminário de Pesquisa da Associação Latino-Americana de Investigadores da Comunicação, ALAIC, em San Juan, Puerto Rico. Pesquisa com apoio do Conselho Nacional de Desenvolvimento Científico e Tecnológico - CNPq - Brasil: Processo nº 462189/2014-7; Chamada MCTI/CNPQ/Universal $14 / 2014$. 
determinados discursos e está aliada aos critérios de verdade vigentes na sociedade".

Neste sentido, manter a estabilidade e a continuidade histórica da instituição é, de certo modo, reafirmar o poder político e ideológico de seus protagonistas, já que as instituições, por mais diferentes que sejam, desempenham um papel social. Ao mesmo tempo em que há uma necessidade de preservação, existe também a responsabilidade sobre o que será mantido, pois este fará parte da memória e da história institucional. Entretanto, na prática da pesquisa documental, é preciso atentar ao que alerta Le Goff (1984):

[...] 0 documento não é inócuo. É antes de mais 0 resultado de uma montagem, consciente ou inconsciente, da história, da época, da sociedade que o produziram, mas também das épocas sucessivas durante as quais continuou a viver, talvez esquecido, durante as quais continuou a ser manipulado, ainda que pelo silêncio (LE GOFF, 1984, p.103).

Ainda que no mundo atual as formas de armazenamento e divulgação tenham se modificado, empresas, instituições e organizações continuam produzindo diferentes materiais que, no futuro, se consolidarão como memória institucional.

Essas informações, encontradas em diversos suportes, devem ser reunidas, fazendo-se mais do que necessária a concentração destes acervos, armazenados e organizados corretamente com a finalidade de estarem disponíveis para consulta porque retratam não só as atividades de uma instituição, mas a época em que está inserida, o tempo e o espaço que ocupa como um todo (RUEDA; FREITAS; VALLS, 2011, p.78).

Mesmo na ambivalência conceitual entre história e memória, parece-nos que é fundamental reconhecer que ambas estão interligadas. A memória produzida e reproduzida pelos sujeitos que fizeram parte de uma instituição comporá a história que ficará gravada. Os registros dessas rememorações, transmitidas por diferentes atores sociais, serão perpetuados em documentos escritos, impressos ou digitalizados - ou em qualquer outro meio que possa eternizar a existência de uma instituição.

\section{Sobre a regulação da cultura}

Stuart Hall (1997) registra que a cultura se encontra no centro das discussões e dos debates contemporâneos e destaca "a enorme expansão de tudo que está associado a ela, na segunda metade do século XX, e o seu papel constitutivo, hoje, em todos os aspectos da vida social" (HALL, 1997, p. 208).

No circuito da cultura de Du Gay et all. (1997) ${ }^{3}$, onde se inicia 0 debate sobre 0 conceito de regulação no âmbito dos Estudos Culturais, o eixo da regulação corresponde à noção de regramento, isto é, leis, normas e convenções através das 
quais as práticas sociais são ordenadas e políticas culturais são implementadas. No âmbito da comunicação, a abrangência desse conceito pode incluir tanto a regulação sobre 0 direito universal de "procurar, receber e transmitir informações e ideais por quaisquer meios e independentemente de fronteiras"4, quanto específicas legislações nacionais, como as leis e os decretos que instituem uma universidade e seu aparato comunicacional.

Para Hall (1997), a esfera da cultura é governada tanto pela tendência à regulação quanto à desregulação, podendo estar associada, no primeiro caso, ao Estado e, no segundo, ao mercado. Em ambas as situações, a cultura é regulada por pressões econômicas e de grupos, bem como de estruturas de poder, e se conecta aos modos de produção econômica e às formas de consumo.

No campo do discurso organizacional contemporâneo, Du Gay (2003, 251-252) afirma que a cultura atua inclusive nas identidades dos sujeitos, uma vez que é vista como meio de produzir “uma relação particular com o 'eu' entre os membros de uma empresa". E as reformas organizacionais passam a ser definidas em termos culturais. Sobretudo, aqueles que trabalham nas grandes organizações estão sujeitos a "programas de 'mudança cultural', como parte dos esforços para tornar as empresas mais eficientes, eficazes e rentáveis". Segundo o autor, quaisquer textos recentes de gestão revelam a primazia dada à "cultura" no governo da vida organizacional contemporânea. Nessa literatura, é atribuída uma posição privilegiada à cultura, pois, conforme seus preceitos, é ela que estrutura o pensamento, 0 sentir e 0 agir das pessoas nas organizações.

0 problema é mudar "regras", "atitudes" e "valores" para que as pessoas tenham a capacidade de dar uma contribuição relevante e necessária para o sucesso da organização para a qual trabalham. Para este fim, os gestores são encorajados a considerar que empresas eficientes ou "de excelência" são aquelas com a "cultura" apropriada: 0 conjunto de regras e técnicas de condução que permite a coordenação de capacidade de autorrealização dos indivíduos com as metas e os objetivos da organização para a qual trabalham (DU GAY, 2003, 252).

Assim, ao mesmo tempo em que existe um "governo da cultura", há um movimento inverso: a "regulação através da cultura". Destacamos aqui a forma normativa de regulação identificada por Hall (1997), ou seja, aquela que guia a ação humana mediante normas associadas a convenções existentes na cultura.

Esse autor argumenta que a regulação normativa formata, direciona e dá propósito a condutas e práticas humanas em sociedade, dotando-as, 
assim, de certos propósitos, fins e intenções, tornando-as previsíveis, regulares, e, dessa forma, criando "um mundo ordenado - no qual cada ação está inscrita nos significados e valores de uma cultura comum a todos" (HALL, 1997, p. 234). Entretanto, ele também alerta para a importância de focalizar as questões ligadas à regulação e ao governo da conduta social nas sociedades da modernidade tardia. E, ao se indagar sobre as razões pelas quais é necessário atentar para 0 que se dá no âmbito da regulação da esfera cultural e sobre a centralidade das questões culturais nos debates acerca das políticas públicas, responde:

No cerne desta questão está a relação entre cultura e poder. Quanto mais importante - mais "central" - se torna a cultura, tanto mais significativas são as forças que a governam, moldam e regulam. Seja 0 que for que tenha a capacidade de influenciar a configuração geral da cultura, de controlar ou determinar o modo como funcionam as instituições culturais ou de regular as práticas culturais, isso exerce um tipo de poder explícito sobre a vida cultural. (HALL, 1997, p. 227-228).

Por outro lado, não se pode descartar que o papel do Estado é, fundamentalmente, o de regulação das questões culturais e de autor e executor de políticas públicas, sobretudo quando se tem em conta não apenas a área da comunicação, mas a comunicação que se pratica em uma universidade federal, como é 0 objeto do presente estudo. Quanto a esse poder regulatório, aponta Hall (2003, p. 163): "0 Estado e a instância de atuação de uma condensação que permite a transformação daquele ponto de interseção das práticas distintas em uma prática sistemática de regulação, de regra e norma, e de normalização dentro da sociedade". Contudo, 0 autor apresenta ainda as possíveis rupturas dadas no contexto da regulação normativa:

Naturalmente, na regulação normativa, com frequência, e sempre no fim, há ruptura - de outra forma, não haveria qualquer mudança, e o mundo repetiria a si mesmo simples e infinitamente. [...] É por esse motivo que as fronteiras da regulação cultural e normativa são um instrumento tão poderoso para definir "quem pertence" (isto é, quem faz as coisas da mesma forma que nós, conforme nossas normas e conceitos) e quem é um "outro", diferente, fora dos limites discursivos e normativos de nosso modo particular de fazer as coisas. (HALL, 1997, p. 234)

E são justamente as rupturas nos sistemas de governo no Brasil que tratamos na seção seguinte, as quais trazem em seu bojo consequências na regulação da vida cultural da UFRGS, determinando em alguns momentos, sob regimes de exceção, como o que se instaurou em março de 1964, quem estava fora não apenas dos limites normativos vigentes, mas da própria universidade.

\section{Regulação da UFRGS sob regimes de exceção}

0 decreto 5.758, de 28 de novembro de 1934, assinado pelo presidente Getúlio Vargas, criou a Universidade de Porto Alegre, que, em 1950, com a federalização, passou a denominar-se Universidade Federal do Rio Grande do Sul UFRGS. A finalidade precípua da instituição era, conforme 0 art. I, alínea b, do decreto de criação "aperfeiçoar a educação intelectual, moral e física 
das nossas gerações, e ministrar conhecimentos culturais e práticas que preparem cidadãos úteis à Nação e à humanidade". Com uma missão tão grandiosa, nasce, assim, a primeira instituição de nível superior no Rio Grande do Sul. Tal missão, no entanto, dá conta de atos regulatórios que não são ingênuos nem desprovidos de propósitos. Sobre a relação entre a esfera da cultura e as forças estatais no contexto do Estado Novo, Ortiz $(2012,80)$ lembra que:

As relações entre cultura e Estado são antigas no Brasil. Se tomarmos um exemplo relativamente recente, o dos anos 1930, veremos que com 0 advento do Estado Novo, 0 aparelho estatal encontra-se associado à expansão da rede das instituições culturais (criação do Serviço Nacional de Teatro), à criação de cursos de ensino superior, e também à elaboração de uma ideologia da cultura brasileira.

Na UFRGS, os anos seguintes foram marcados por fortes protestos dos estudantes e uma greve que durou quase 90 dias e obteve grande repercussão social. 0 período de 1952 a 1964 foi de expansão física, em que várias faculdades ganharam suas próprias sedes; da construção do prédio da Reitoria (1957), que passou a integrar a vida social da cidade com seus bailes, formaturas e promoções culturais; à elaboração de projetos para os campi, como o "Plano piloto da cidade universitária de Porto Alegre", no Vale da Agronomia, e do início da obra do Hospital de Clínicas. Na parte acadêmica, houve a criação de muitos cursos e reestruturação de outros, em plena era de "0 petróleo é nosso" e "Fora com os americanos", decidiu-se criar o curso de Geologia com a ideia de torná-lo um dos melhores do país, e, para isso, trouxeram diversos docentes estrangeiros, inclusive norte-americanos.

Vigorava a Guerra Fria e, com temor de que os países latino-americanos seguissem as ideias comunistas ou se inspirassem na Revolução Cubana (1959), os Estados Unidos intensificaram alguns e criaram outros programas com 0 objetivo de subsidiar 0 desenvolvimento capitalista no terceiromundo. 0 "Ponto Quatro" (1949), expansão para essas regiões do Plano Marshall (que havia sido criado dois anos antes para incentivar a reconstrução econômica de 17 países europeus), chegou a financiar alguns projetos da instituição em diferentes momentos. Exemplo disso foi a "Aliança para o Progresso", criada por John Kennedy (1961) com a finalidade de prestar colaboração financeira e técnica na América Latina, que ganhou uma agência específica para a mobilização das operações - a United State Agency for International Development. Através dessa agência, foram assinados diversos acordos na área da educação entre Brasil e Estados Unidos, chamados de MEC-Usaid (Ministério da Educação e Cultura e United State Agency for International Development) e que beneficiaram muitos grupos de pesquisa da UFRGS, seja através da aquisição de equipamentos importados, seja pelo apoio econômico para a realização de estudos no exterior. 
Em 31 de março de 1964, a vida social, econômica e, sobretudo, política do país passou por uma abrupta e radical transformação, com a tomada do poder pelas forças militares. 0 que vários chamam de "golpe de Estado", outros de "golpe militar" e alguns de "revolução de 64" se consolidou em um regime de governo que vigorou até 1985, repercutindo com força no meio acadêmico. Nessa ocasião, a repressão a ideias contrárias à ditadura se fez presente em todas as universidades brasileiras, e a UFRGS não foi exceção. Já em um primeiro momento, houve uma série de prisões e cassações no meio acadêmico, e uma das faculdades mais afetadas nesse sentido foi a de Filosofia, unidade que reunia várias áreas do conhecimento, onde se consolidava um espaço de debates sobre todos os temas e também de intensa politização e de resistência. Foram proibidas as tradicionais, famosas e - para muitos - saudosas "paradas dos bixos", em que os alunos expunham, de maneira debochada, cômica e irreverente suas críticas ao sistema.

De forma ainda mais acentuada do que no Estado Novo, a ditadura militar criou uma gama de órgãos, regulando as diferentes áreas da cultura. Ortiz (2012, p. 86) contabiliza entre 1965 e 1979 a criação e transformação de 16 órgãos, dentre os quais se destacam a Embratel, o Conselho Federal de Cultura, a Embratur, 0 Instituto Nacional de Cinema, a Embrafilme, a Telebrás, a Funarte, o Concine, a Radiobrás, a Secretaria do Patrimônio Histórico e Artístico Nacional e a Fundação Pró-Memória.
Mas, para além da sanha regulatória da ditadura, foi em 1968, quando os militares publicaram o Ato Institucional $n^{0} 5$ (AI-5), limitando as liberdades individuais, que a UFRGS perdeu muitos de seus docentes. 0 expurgo se dava sob a forma de aposentadoria compulsória ou demissão. Os debates e as manifestações foram definitivamente abafados, e a política deixou de fazer parte do cotidiano da vida acadêmica, sob a égide do "AI 5 das universidades":

0 decreto-lei $n^{0} 477$, de 26 de fevereiro de 1969, também chamado de "Al-5 das universidades", foi um ato baixado pelo então ditador general Artur da Costa e Silva, durante a ditadura, que punia professores, alunos e funcionários de universidades acusados de subversão ao regime com expulsão. Na prática, visava inibir a capacidade intelectual de uma geração de acadêmicos. 0 processo a que se submetia 0 acusado era sumário. 0 s professores atingidos ficavam impossibilitados de trabalhar em outra instituição educacional por cinco anos, ao passo que os estudantes ficavam proibidos de cursarem qualquer universidade por três anos. (PALMAR, 2012, p. 1)

Ainda em 1968, o governo baixava uma lei (Lei 5.540) em que fixava as normas de organização e funcionamento das universidades brasileiras. Gerando as mais diferentes e até opostas reações e sentimentos, a chamada "Reforma Universitária", implantada na UFRGS em 1970, deu à instituição a sua estrutura atual, baseada em departamentos que formam institutos e faculdades.

Sintetizando, Rubim $(2013,226)$ afirma que apenas nos períodos de regimes autoritários 0 Brasil contou com políticas culturais nas quais 0 Estado assumiu um papel mais ativo: 
As ditaduras do Estado Novo (1937-1945) e dos militares (1964-1985), além da censura, repressão, medo, prisões, tortura, assassinatos, exílios inerentes a todo e qualquer regime autoritário, realizaram uma intervenção potente no campo cultural. Por certo tal atuação visava instrumentalizar a cultura; domesticar seu caráter crítico; submetê-la aos interesses autoritários; buscar sua utilização como fator de legitimação das ditaduras e, por vezes, como meio para a conformação de um imaginário de nacionalidade.

Foi em meio a esse clima, em que muitos foram silenciados, outros tantos expurgados, que 0 então reitor Ivo Wolff criou o órgão que teria como função divulgar, de forma mais ampla, as atividades realizadas pela Universidade. A Assessoria de Imprensa passaria a ser um importante instrumento de propagação dessas ações, seguindo a ótica particular e o crivo do Gabinete do Reitor.

\begin{abstract}
A boa atuação de uma assessoria aumenta a visibilidade pública das organizações e pode trazer efeitos mercadológicos e políticos predeterminados. Por perceber isso é que, cada vez mais, instituições brasileiras têm interesse em divulgar suas atividades e propostas pelos meios de comunicação, buscando influenciar a opinião pública (DUARTE, 2002: 90).
\end{abstract}

Em um ofício circular, expedido pelo Gabinete do Reitor a todos os setores da instituição, 0 reitor dá ciência da implementação do AI com a seguinte redação:

Of. Circular n 979/72-GAB -Porto Alegre, 22 de agosto de 1972

Senhor (a):

Tenho a satisfação de levar ao conhecimento de
V. Sa. que através da Portaria $n^{0} 729$, desta data, foi criada a Assessoria de Imprensa da Universidade Federal do Rio Grande do Sul, a qual funcionará junto ao Gabinete do Reitor.

Informo a V. Sa. que a Assessoria em apreço, além de editar o INFORMATIVO DA UFRGS, periódico oficial desta Universidade, terá a seu encargo a coleta de notícias relacionadas com a Universidade, distribuindo-as, posteriormente, aos órgãos de comunicação social para divulgação.

Assim sendo, todas as notícias de interesse dessa Unidade deverão ser encaminhadas à mencionada Assessoria, que se encarregará da elaboração do texto final para publicação.

Agradeço as providências que V. Sa. determinar objetivando o cumprimento do presente e colho o ensejo para reiterar protestos de estima e consideração.

Professor IVO WOLFF

Reitor

A instalação formal da Assessoria de Imprensa, de certo modo, daria mais visibilidade ao Informativo da UFRGS, criado em março de 1971, pelo reitor Eduardo Faraco. Este veículo oficial de divulgação veio para substituir o Boletim de Pessoal, publicação de caráter legal e obrigatório, na qual constavam apenas os atos legais e as decisões formais. Sob o título "Uma Nova Perspectiva", o editorial do primeiro número do Informativo justificava sua criação como "a positiva tendência de criar ao funcionalismo da Universidade melhores meios de comunicação, efetivamente condizentes com as necessidades do nosso tempo". A redação segue ainda com a seguinte mensagem:

[...] A Universidade Federal do Rio Grande do Sul, como estabelecimento de ensino superior e como Órgão da Administração Federal que é, sofre no momento grandes e profundas trans- 
formações, juntamente com 0 todo 0 sistema de ensino superior nacional. A hora é de reformas. E a Reforma Universitária, assim como a Reforma Administrativa, estão a preconizar novas estruturações mais racionais e produtivas. Nesse sentido orienta-se tôda nossa vitalidade criativa e capacidade de organização. Os corpos docentes, técnico e administrativo têm sôbre si, práticamente, tôda a responsabilidade do que resultar 0 atual esfôrço conjunto. Não carência de meios - temos aqui entre nós grandes capacidades, pessoas que pelos seus dotes podem planejar e executar a imensa tarefa proposta, fazendo uso dos recursos humanos e materiais já existentes (INFORMATIVO DA UFRGS, 1971: 2).

Seguindo na marcha do regime militar, a UFRGS concebeu seu aparato de comunicação de forma vertical, de modo a privilegiar primordialmente a imagem dos governos, depois das administrações e, em último plano, a da instituição. Nas edições de sua publicação oficial - 0 Informativo da UFRGS -, não é feita nenhuma menção sobre os milhares de estudantes que foram torturados nos porões da ditadura, tampouco ao expurgo de dezenas de professores. Era um tempo para viver a Reforma Universitária, era um tempo para usufruir do "milagre econômico" brasileiro.

\section{Regulação da UFRGS sob a égide do neoliberalismo}

Duas décadas depois, porém, de um simples setor de atendimento ao gabinete do reitor, a Assessoria de Imprensa diversifica-se e se torna uma Coordenadoria de Comunicação Social, cujo ato regulatório esclarece se voltar às relações com a imprensa e, ainda, aos setores do audiovisual e a atividades características da área das Relações Públicas (é criada uma divisão com este nome).

Portaria $\mathrm{n}^{0}$ 4356, de 13 de outubro de 1993

0 Reitor da Universidade Federal do Rio Grande do Sul, no uso de suas atribuições, considerando a necessidade de implantar um sistema integrado de comunicação social na Universidade, visando à informação de sua coletividade interna e da sociedade,

considerando a necessidade de oferecer a todos os órgãos da Universidade nas áreas de publicações, relações com a imprensa, planejamento gráfico, comunicação audiovisual, relações públicas, protocolo e cerimonial

RESOLVE

Criar no Gabinete do Reitor, com efeitos a partir de 19 de julho de 1993, a Coordenadoria de Comunicação Social da Universidade, composta de Divisão de Publicações e Relações com a Imprensa, Divisão de Comunicação Visual e Audiovisual, Divisão de Relações Públicas, Gráfica Universitária e Secretaria, revogando-se a Portaria $\mathrm{n}^{0} 729$, de 22 de agosto de 1972, e os atos subsequentes que tratem da mesma matéria. Helgio Trindade

Reitor

Onze anos mais tarde, a Coordenadoria assume o caráter de Secretaria de Comunicação Social, em portaria que não faz nenhuma referência a atribuições da Comunicação, dando sinal de novos tempos, se não de desregulação, mas de enxugamento dos normativos regulatórios.

Portaria $n^{0} 2.482$, de 07 de outubro de 2004 0 Reitor da Universidade Federal do Rio Grande do Sul, no uso de suas atribuições,

RESOLVE: 
Criar a Secretaria de Comunicação Social da Universidade Federal do Rio Grande do Sul, a partir de $1^{\circ}$ de outubro de 2004.

José Carlos Ferraz Hennemann

Reitor

Os documentos oficiais aqui apresentados norteiam as ações da comunicação da UFRGS e servem como importante ferramenta para contextualizar e discutir o seu papel nos dias atuais. Falar sobre comunicação é falar sobre poderes: 0 de intervir e 0 de mudar. É falar de instituições e sujeitos que conduzem, geram e difundem informações capazes de interferir na realidade. Apesar de não haver um plano formal a ser executado pela Secretaria de Comunicação Social da UFRGS, que ainda seja um setor vinculado ao gabinete do reitor e, por isso, passível de sofrer mudanças em suas diretrizes a cada novo dirigente que assume.

Contemporaneamente, a importância estratégica da comunicação cresce na medida em que se desregulamentam os mercados financeiros globais, e novas formas transnacionais de produção e consumo passam a ter valor de regulação sobre um capital global. Este, que prevê "fluxos de moeda grandes 0 suficiente para desestabilizar as economias médias", dá espaço ao que Hall (2003, p.58) chama de "economia do conhecimento", ou seja, o "crescimento exponencial de novas indústrias culturais impulsionado pelas tecnologias de informação", que se instaura a partir dos anos 1970, com pequenas variações de data neste ou naquele país.
No âmbito das assessorias de imprensa ou gabinetes de comunicação social, como também são conhecidas, esta "economia do conhecimento" assume, atualmente, os mais variados formatos. E sob esses formatos estão presentes, como indica Duarte (2002), na estrutura pública, isto é, em empresas estatais e nos poderes executivo (incluindo-se aí as universidades), legislativo e judiciário, da mesma forma que no terceiro setor e nos movimentos sociais (de Organizações Não Governamentais a sindicatos e ao Movimento dos Trabalhadores Rurais Sem Terra) e, até mesmo, na divulgação de pessoas físicas (de artistas a políticos).

\section{Considerações finais}

Retomando a constatação de Ortiz (2012, p. 79), de que "para se pensar como se estrutura atualmente 0 campo da cultura é necessário levar-se em consideração a atuação do Estado brasileiro, que, sem dúvida alguma, é um dos elementos dinâmicos e definidores da problemática cultural", percebe-se que, para além dos direcionamentos das políticas públicas voltadas à cultura e, mais especificamente, às universidades, que 0 artigo focou, há na Secretaria de Comunicação da UFRGS outros pontos para reflexão.

A comunicação da Universidade foi concebida de forma vertical, de modo a privilegiar primordialmente a imagem dos governos, depois das administrações e, em último plano, a da instituição. As mais novas 
concepções de comunicação institucional apontam para a necessidade de inverter essa lógica. Mudar essa visão e reforçar a imagem da instituição é mudar uma cultura há décadas instituída, é olhar para frente e perceber que as mudanças são imperiosas.

Assim, apesar de ter havido avanços e algumas iniciativas no sentido de atualizar métodos e formas de fazer comunicação na UFRGS, a cultura introjetada desde a criação do setor se perpetua. A comunicação não mudou de modo suficiente a ponto de modificar a estrutura hierárquica predominante, qual seja, a de não atender prioritariamente às demandas dos diferentes órgãos que compõem a instituição, no sentido de propagar e disseminar a produção desenvolvida nas áreas de Ensino, Pesquisa e Extensão.

A Universidade Federal do Rio Grande do Sul é uma instituição secular, pois, apesar de ter sido federalizada há 80 anos, é possível localizar a sua origem no século XIX, quando foram criadas unidades isoladas, como as escolas de Farmácia e Química e as faculdades de Engenharia, Medicina e Direito. Ao longo da sua história, a Universidade cresceu, ampliou as suas áreas de atuação, abriu fronteiras para o mundo. Todavia, embora tenha se tornado uma instituição de destaque nacional e internacional, de ter sido considerada pelo Ministério da Educação a melhor Universidade do Brasil em avaliações feitas em 2011 e 2012, seu setor de comunicação não se desenvolveu na mesma proporção que a Universidade como um todo. Não há um plano de comunicação em vigor que possa garantir a continuidade das atividades da Secretaria de Comunicação Social, especialmente no que se refere à sua Assessoria de Imprensa, já que é para este setor que são encaminhadas as principais demandas de divulgação de informações. Somente uma comunicação integrada, com uma política e com objetivos definidos, poderá responder àqueles que aguardam 0 exercício de suas funções. Um sistema de comunicação organizado e sistematizado é indispensável para contemplar necessidades internas e externas, uma vez que não há justificativas para a falta de acesso ou de acesso restrito a um grupo privilegiado de todo 0 conhecimento produzido pela Universidade.

Assim, se, de um lado, percebe-se uma forte regulação política das universidades, especialmente nos períodos ditatoriais, de outro, se carece de atos regulatórios no setor de comunicação que a tornem menos uma assessoria de governos ou de reitores e mais um serviço à comunidade universitária.

\section{Referências}

CHAPARRO, M. C. Cem Anos de Assessoria de Imprensa. In DUARTE, Jorge (org.) Assessoria de Imprensa e relacionamento com a mídia: teoria e técnica. Atlas, 2002.

COSTA, Icléia Thiesen Magalhães. Memória institucional: a construção conceitual numa abordagem teórico-metodológica. Tese de doutorado apresentada ao Programa de Pós-graduação em Ciências da Informação da Universidade Federal do Rio de Janeiro (ECO/UFRJ). Rio de Janeiro, 1997. 
DU GAY, P. et al. Doing Cultural Studies: The story of the Sony Walkman. Londres: Sage, 1997.

DU GAY, P. Organización de la identidad: gobierno empresarial y gestión pública. In HALL, Stuart; DU GAY, Paul (org.) Cuestiones de identidad cultural. Buenos Aires: Amorrortu, 2003. p. 251-280.

DUARTE, J (org.) Assessoria de Imprensa e relacionamento com a mídia: teoria e técnica. Atlas, 2002.

HALL, S. The centrality of culture: notes on the cultural revolutions of our time. In: THOMPSON, Kenneth (org.) Media and Cultural Regulation. London: Sage, 1997, p. 207-238. (Tradução brasileira: A centralidade da cultura: notas sobre as revoluções culturais de nosso tempo. Revista Educação e Realidade, Porto Alegre, v. $22, n^{0} .2$, jul./dez. 1997. p. 15-46).

. A questão multicultural. In HALL, Stuart.

Da diáspora. Identidades e mediações culturais.

Organização Liv Sovik. Belo Horizonte: Editora UFMG, 2003. p.51-100.

Significação, representação, ideologia:

Althusser e os debates pós-estruturalistas. In HALL, Stuart. Da diáspora. Identidades e mediações culturais. Organização Liv Sovik. Belo Horizonte: Editora UFMG, 2003, p.160-198.

LE GOFF, J (Coord.). Memória e história. Lisboa: Imprensa Nacional, Casa da Moeda, 1984.

MOREIRA, S. V. M. Análise documental como método e como técnica. In DUARTE, J e BARROS, A. Métodos e técnicas de pesquisa em comunicação. São Paulo: Atlas, 2005, p. 269-279.

ORTIZ, R. Estado autoritário e cultura. In ORTIZ, R.

Cultura brasileira e identidade nacional. São Paulo: Brasiliense, 2012, p. 79-126.
PALMAR, A. Lei 477 - 0 AI5 das universidades. Site Documentos Revelados, $1^{0}$ jun.2012. Disponível em http://www.documentosrevelados.com.br/repressao/ forcas-armadas/lei-477-0-ai5-das-universidades/ Acesso em 15/03/2015.

RUBIM, A. A. C. Políticas culturais do governo Lula.

Revista Lusófona de Estudos Culturais, v. 1, n. 1, p. 224-242, 2013. Disponível em: http://estudosculturais. com/revistalusofona/index.php/rlec/article/view/17/43. Acesso em 12/07/2015.

RUEDA, Valéria Matias da Silva; FREITAS, Aline de; VALLS, Valéria Martin. Memória Institucional: uma revisão de literatura. CRB-8 Digital, São Paulo, v. 4, n. 1, p. 78-89, abr. 2011. Disponível em http://www.revista. crb8.org.br/index.php/crb8digital/article/viewFile/62/64. Acesso em 21/09/2015.

UNIVERSIDADE FEDERAL DO RIO GRANDE DO SUL. Decreto 5.758, de 28/11/1934.

UNIVERSIDADE FEDERAL DO RIO GRANDE DO SUL. Portaria $n^{0} 729$, de 22/08/1972.

UNIVERSIDADE FEDERAL DO RIO GRANDE DO SUL. Portaria $n^{0} 4356$, de 13/10/1993.

UNIVERSIDADE FEDERAL DO RIO GRANDE DO SUL. Portaria $n^{0} 2482$, de 07/10/2004.

UNIVERSIDADE FEDERAL DO RIO GRANDE DO SUL. Plano de Desenvolvimento Institucional da UFRGS $2011 / 2015$. 


\begin{tabular}{|c|c|}
\hline $\begin{array}{l}\text { Memory of regulatory acts in } \\
\text { communication at UFRGS: an } \\
\text { analytical proposal }\end{array}$ & $\begin{array}{l}\text { Memoria de actos reglamentarios } \\
\text { en la comunicación de la UFRGS: } \\
\text { una propuesta analítica }\end{array}$ \\
\hline $\begin{array}{l}\text { Abstract } \\
\text { Theoretically endorsing in Hall (1997), this paper } \\
\text { proposes a reflection on the regulatory acts related } \\
\text { to the communication sector of the Federal University } \\
\text { of Rio Grande do Sul (UFRGS), with emphasis on the } \\
\text { memory of the Press Office. Through documentary } \\
\text { research, we examined the roles and objectives } \\
\text { for which the university and the department was } \\
\text { regulated, both in dictatorial and neoliberalism } \\
\text { periods, concluding that if in these are the trend is } \\
\text { deregulation, and dictatorships are characterized by } \\
\text { regulation of the culture. Finally, we discuss how the } \\
\text { Press Office is nowadays systematizing activities and } \\
\text { creating standards and policies for its operations. } \\
\text { Keywords } \\
\text { Institutional Memory. Culture. } \\
\text { Communication Regulation. }\end{array}$ & $\begin{array}{l}\text { Resumen } \\
\text { Respaldado teóricamente en Hall (1997), este artículo } \\
\text { propone una reflexión sobre los actos reglamentarios } \\
\text { relacionados con el sector de la comunicación, de la } \\
\text { Universidad Federal de Río Grande do Sul (UFRGS), } \\
\text { con énfasis en la memoria de la Oficina de Prensa. A } \\
\text { través de la investigación documental, se examinaron } \\
\text { las funciones y objetivos para los que se regulan la } \\
\text { universidad y la industria, nos sostiene en los períodos } \\
\text { dictatoriales y bajo el neoliberalismo, concluyendo que } \\
\text { si éstos la tendencia es la desregulación, las dictaduras } \\
\text { se caracterizan por la cultura de la regulación. } \\
\text { Finalmente, se discute, en estos días, ya que la oficina } \\
\text { de prensa viene sistematizando las actividades y la } \\
\text { creación de normas y políticas para sus operaciones. } \\
\text { Palabras clave } \\
\text { Memoria Institucional. Cultura. }\end{array}$ \\
\hline
\end{tabular}




\section{Expediente}

A revista E-Compós é a publicação científica em formato eletrônico da Associação Nacional dos Programas de Pós-Graduação em Comunicação (Compós). Lançada em 2004, tem como principal finalidade difundir a produção acadêmica de pesquisadores da área de Comunicação, inseridos em instituições do Brasil e do exterior.

\section{E-COMPÓS I www.e-compos.org.br I E-ISSN 1808-2599}

Revista da Associação Nacional dos Programas de Pós-Graduação em Comunicação.

Brasília, v.18, n.3, set./dez. 2015.

A identificação das edições, a partir de 2008, passa a ser volume anual com três números.

Indexada por Latindex I www.latindex.unam.mx

\section{CONSELHO EDITORIAL}

Alexandre Farbiarz, Universidade Federal Fluminense, Brasil Alexandre Rocha da Silva, Universidade Federal do Rio Grande do Sul, Brasil Ana Carolina Damboriarena Escosteguy, Pontifícia Universidade Católica do Rio Grande do Sul, Brasil

Ana Carolina Rocha Pessôa Temer, Universidade Federal de Goiás, Brasil Ana Regina Barros Rego Leal, Universidade Federal do Piauí, Brasil Andrea França, Pontifícia Universidade Católica do Rio de Janeiro, Brasil André Luiz Martins Lemos, Universidade Federal da Bahia, Brasil Antonio Carlos Hohlfeldt, Pontifícia Universidade Católica do Rio Grande do Sul, Brasil

Arthur Ituassu, Pontifícia Universidade Católica do Rio de Janeiro, Brasil Álvaro Larangeira, Universidade Tuiuti do Paraná, Brasil Ângela Freire Prysthon, Universidade Federal de Pernambuco, Brasil César Geraldo Guimarães, Universidade Federal de Minas Gerais, Brasil Cláudio Novaes Pinto Coelho, Faculdade Cásper Líbero, Brasil Daisi Irmgard Vogel, Universidade Federal de Santa Catarina, Brasil Denize Correa Araujo, Universidade Tuiuti do Paraná, Brasil Eduardo Antonio de Jesus, Pontifícia Universidade Católica de Minas Gerais, Brasil

Daniela Zanetti, Universidade Federal do Espirito Santo, Brasil Eduardo Vicente, Universidade de São Paulo, Brasil Elizabeth Moraes Gonçalves, Universidade Metodista de São Paulo, Brasil Erick Felinto de Oliveira, Universidade do Estado do Rio de Janeiro, Brasil Francisco Elinaldo Teixeira, Universidade Estadual de Campinas, Brasil Francisco Paulo Jamil Almeida Marques, Universidade Federal do Paraná, Brasil

Gabriela Reinaldo, Universidade Federal do Ceará, Brasil Goiamérico Felício Carneiro Santos, Universidade Federal de Goiás, Brasil Gustavo Daudt Fischer, Universidade do Vale do Rio dos Sinos, Brasil Herom Vargas, Universidade Municipal de São Caetano do Sul, Brasil Itania Maria Mota Gomes, Universidade Federal da Bahia, Brasil
Janice Caiafa, Universidade Federal do Rio de Janeiro, Brasil Jiani Adriana Bonin, Universidade do Vale do Rio dos Sinos, Brasil José Afonso da Silva Junior, Universidade Federal de Pernambuco, Brasil José Luiz Aidar Prado, Pontifícia Universidade Católica de São Paulo, Brasil Juçara Gorski Brittes, Universidade Federal de Ouro Preto, Brasil Kati Caetano, Universidade Tuiuti do Paraná, Brasil

Lilian Cristina Monteiro França, Universidade Federal de Sergipe, Brasil Liziane Soares Guazina, Universidade de Brasília, Brasil Luíza Mônica Assis da Silva, Universidade de Caxias do Sul, Brasil Luciana Miranda Costa, Universidade Federal do Pará, Brasil Malena Segura Contrera, Universidade Paulista, Brasil Maria Ogécia Drigo, Universidade de Sorocaba, Brasil Maria Ataide Malcher, Universidade Federal do Pará, Brasil Marcia Tondato, Escola Superior de Propaganda e Marketing, Brasil Marcel Vieira Barreto Silva, Universidade Federal da Paraíba, Brasil Maria Clotilde Perez Rodrigues, Universidade de São Paulo, Brasil Maria das Graças Pinto Coelho, Universidade Federal do Rio Grande do Norte, Brasil

Mauricio Ribeiro da Silva, Universidade Paulista, Brasil

Mauro de Souza Ventura, Universidade Estadual Paulista, Brasil Márcio Souza Gonçalves, Universidade do Estado do Rio de Janeiro, Brasil Micael Maiolino Herschmann, Universidade Federal do Rio de Janeiro, Brasil Mirna Feitoza Pereira, Universidade Federal do Amazonas, Brasil Nísia Martins Rosario, Universidade Federal do Rio Grande do Sul, Brasil Potiguara Mendes Silveira Jr, Universidade Federal de Juiz de Fora, Brasil Regiane Regina Ribeiro, Universidade Federal do Paraná, Brasil Rogério Ferraraz, Universidade Anhembi Morumbi, Brasil Rose Melo Rocha, Escola Superior de Propaganda e Marketing, Brasil Rozinaldo Antonio Miani, Universidade Estadual de Londrina, Brasil Sérgio Luiz Gadini, Universidade Estadual de Ponta Grossa, Brasil Simone Maria Andrade Pereira de Sá, Universidade Federal Fluminense, Brasil Veneza Mayora Ronsini, Universidade Federal de Santa Maria, Brasil Walmir Albuquerque Barbosa, Universidade Federal do Amazonas, Brasil

\section{COMISSÃO EDITORIAL}

Cristiane Freitas Gutfreind

Pontifícia Universidade Católica do Rio Grande do Sul, Brasil

Irene Machado

Universidade de São Paulo, Brasil

\section{CONSULTORES AD HOC}

Claudia Peixoto de Moura, Pontificia Universidade Católica do Rio Grande do Sul, Brasil Francisco Rüdiger, Pontifícia Universidade Católica do Rio Grande do Sul, Brasil Juremir Machado da Silva, Pontifícia Universidade Católica do Rio Grande do Sul, Brasil Maria Aparecida Baccega, Universidade de São Paulo, Brasil

Roberto Tietzmann, Pontifícia Universidade Católica do Rio Grande do Sul, Brasil

\section{EQUIPE TÉCNICA}

ASSISTENTE EDITORIAL I Márcio Zanetti Negrini

REVISÃO DE TEXTOS I Press Revisão

EDITORAÇÃO ELETRÔNICA I Roka Estúdio

CONTATO I revistaecompos@gmail.com
COMPÓS I www.compos.org.br

Associação Nacional dos Programas de Pós-Graduação em Comunicação

Presidente

Edson Fernando Dalmonte

Programa de Pós-Graduação em Comunicação

e Cultura Contemporânea - UFBA

edsondalmonte@uol.com.br

Vice-presidente

Cristiane Freitas Gutfreind

Programa de Pós-Graduação em Comunicação Social - PUC-RS cristianefreitas@pucrs.br

Secretário-Geral

Rogério Ferraraz

Programa de Pós-Graduação em Comunicação

Universidade Anhembi Morumbi

rogerioferraraz@anhembimorumbi.edu.br 